\section{Integration does make a difference}

\section{Anastasia Vlachou}

\author{
Research Student \\ Department of Education \\ University of Sheffield \\ U.K.
}

This paper is an attempt to present some of the mechanisms which contribute in promoting integration as a regular educational activity, and not as a distinctive special task which has to be transplanted in ordinary educational programming. Continuity, participation and an extended notion of integration are integral parts of such mechanisms.

\section{Acknowledgements}

The author is grateful to all the teachers and the children who participated in this study. The support and guidance of my supervisor Professor Len Barton and the valuable editing of this paper by Dr. Peter Mayo are also gratefully acknowledged. Finally, the research reported in this paper was partially supported by The Greek Scholarship Foundation.

(C) 1993,1999. The Down Syndrome Educational Trust Down Syndrome Research and Practivce

1993, 1 (3) 95-100
Introduction

Five assumptions have been identified, although it has not been claimed that there were no other factors which were important in the formulation of the Acts towards the integration of students with special needs.

Stigma reduction, wider social and racial composition in classes, higher academic achievement, and a better social adjustment in school and life were assumed to be the underlying benefits of regular education of children with special needs.

Previous theoretical and empirical research, both in a British and American context, examining the degree to which integrated settings have fulfilled their aims, provide us with inconclusive results (Carroll, 1967; Gickling et al., 1975; Gottlieb, 1974; Johnson and Johnson, 1981; Hegarty et al., 1989; Pieterse \& Center, 1984; Jenkins et al., 1989; Bromfield et al., 1986; Dissent, 1987; Casey et al., 1988; Dandy \& Cullen, 1988; Karagiannis, 1988) (1).

There were and there still are arguments against or in favour of the implementation and the effectiveness of integration policies and practices. This is natural if one considers that integration is a non-linear learning process encompassing a revolution in thinking and a different way of living. As Uditsky (1993) puts it:

Inclusive education may take generations before it is properly understood or practised. Exclusion and segregation were built on centuries of devaluation. Those of us who are parents or teachers have not grown up or been immersed in a culture where inclusion and friendship with persons with a disability is an ordinary and typical life occurrence (p. 45).

It is not coincidental that we may find so many different forms of integrated settings, almost as many as there are categories of special needs. As with many aspects of educational programming, integration may be viewed from different perspectives by different interest groups (i.e parents, teachers, children, researchers, psychologists, politicians). At one end of the continuum integration may be viewed as a cheap alternative to special schooling which will do more harm than good. At the other end it may be viewed as an inclusive alternative in which :

the student with a significant disability regardless of the degree or nature of disability is a welcomed and valued member. The student is taught by the regular classroom teacher (who is supported as needed), follows the regular curriculum (with modification and adaptation), makes friends and contributes to the learning of the entire class (Uditsky, 1993, p.48).

Even though integration is a highly complicated idea, difficult in its implementation, surrounded by different or conflicting cultural and socio-political ideologies previous experience has taught us that:

a) Special schools with curricula specifically designed for children with special educational needs, with lower teacherstudent ratios with more specialised staff, do not necessarily facilitate better improvements in general cognitive ability (Casey et al., 1988) and do not equip children with the 
necessary skills for living an independent life (Buckley and Sacks, 1987)

b) Physical contact between children with special needs and the supposedly normal will not on its own be sufficient to produce or explain changes in academic attainment and social interaction (Casey et. al., 1988, p.280),

\section{and}

c) Since a large part of any classroom time is spent in learning activities, the structure given to student learning tasks has a major impact on student-student interaction. When learning is primarily structured as something done individually, interaction opportunities are restricted. Restructuring the way students carry out their learning tasks is a critical intervention for promoting integration (Hoben, 1980 p. 103)

Additionally, the majority of previous research regarding the benefits of integration policies and practices have focused mainly on one interest group: students with special needs. However, integration is a two-way process affecting not only students with special needs but the persons they interact with (i.e. teachers, peers). Exploring the effectiveness of integration practices includes the exploration of the impact that the social infrastructure of the educational environment has upon integration. This in turn influences the cognitive and social development of both students with special needs and their peers.

\section{Further, it has not been acknowledged that:}

Inclusive education necessitates a reconsideration of the complex and potent cocktail of pedagogy, curriculum, school organisation and the ideologies that inform these components of schooling (Slee, 1993 p.351).

In my effort to explore and understand how students perceive their interactions with their peers with Down's syndrome, I realised that I had to focus my attention on the messages that children were receiving from their educational environment. I understood that

elements as diverse and basic as how the room was arranged physically, when and where the handicapped students received special education service, and how learning activities were organised all had an impact on the opportunity for and the patterns of student interaction (Hoben, 1980, p.103).

I acknowledge that children receive messages and information about disability issues from other social institutions as well, the family and the mass media being highly important. However, in school they have the opportunity to encounter children with special needs for a significant amount of time. Thus, they had the opportunity to test, reject, modify or strengthen the ideas that they had obtained from the other sources.

Thus, this discussion will attempt to:

- present the way teachers define integration, hence, the way they perceive the aims of education; and - explore the directions in which teachers orientate their activities in their efforts to promote the type of integration they wished to promote.

It is important to mention that the main focus of this paper is on those mechanisms of ordinary education that simultaneously enhance and promote integration practices. This, however, does not mean that the application of these mechanisms take place without conflicts, tensions and diverse ideological assumptions that co-exist in the same context.

\section{Methodological Issues}

The findings of this paper derive from data obtained at a Yorkshire primary school which educates approximately three hundred and forty children. This school has an integrated resource for children with learning difficulties including six children with Down's syndrome. The school has been implementing an integration policy for the last seven years and today it caters for approximately thirty students with special needs. Children come into the resource on a statement of special needs.

Participants in this study were both teachers and children; however, the findings of this paper are based on data obtained by

a) formal semi-structured interviews, lasting from one up to two and a half hours, with nineteen both regular and special teachers,

b) informal discussions with teachers that took place during break time and finally, from participant observations over one and a half years. Specifically, extensive whole day participant observations took place in three classes. Participant observations were mainly an "open-ended" endeavour to capture not only the happenings but the interpretations ascribed to these happenings by the participants of the study.

This did not involve any pre-specified coding schedule as the researcher was interested not only in figuring out overt observable behaviours but also in discovering the participants' actual or perceived intentions. The nature of this method is in congruence with the nature of the objective of the study which is mainly to explore meanings regarding different situations and not to measure them.

\section{Defining integration or defining education?}

Definitions of integration encompass ideological assumptions, educational priorities and help to form aims that may be extended or altered during the process. The way teachers define integration is a starting point as the meaning they ascribe to it influences their everyday practices. Both the theoretical and the practical form that the notion of integration takes is highly related to the way teachers understand their function as educators. It seems that the effectiveness and the quality of educating children with special needs in ordinary schools cannot be examined apart from teachers' philosophy about education. As a teacher said:

There is always a debate in education about whether we should be educating children so that they can perform well in their working life, teaching kids skills that they'll need in their occupation and there is 
another group, another school of thought which says: no, what we should be doing is educating children to be better human beings and to be more aware of the world, more environmentally aware, more tolerant of sexual and social differences, to learn that they should respect someone who is different from them. My philosophy is both, not one or the other. We can do both: we can educate children for their jobs and for their life.

In this ideological environment, the teachers, who were involved in this study strive to create educational practices in which everybody has a place, accepting the child's strengths and weaknesses. Some teachers even accepted that the diversity of the children they had to teach was one among other reasons that led them to restructure their way of thinking about the aims of education and of integration. The inclusion of children with special needs in their classes had an effect upon their classroom management and upon themselves as professionals. As a female teacher pinpointed:

\begin{abstract}
... the main change for me started when we had the integrated resource. . . I had to change how I approached my class. . . I think we all have to look and see that everybody has needs of a different nature and try to understand this and this is how we try to educate the children. . . I think it is very hard. For myself personally I have learned a lot from dealing with children with special needs that would never have been brought into my experience had it not been for this resource, and I think for children to grow up knowing that there are people with special needs is the right way round, not wait until adulthood.
\end{abstract}

The way someone perceives integration reflects personal values which in turn are being reflected in education's practices and policies. Further, integration offers the opportunity to restructure and rethink our values and priorities. These values cannot be insulated from the society in which they have been created. Even though teachers believed that every child has a right to education they often received conflicting messages that obscured their practices.

The teachers stated that the movement of integration becomes complicated and even 'fragile' when they had to deal with pressures and ideologies that connect education with marketing, competition and exclusion of students that for a variety of reasons could not achieve the standards that had been predetermined by external sources.

The teachers involved in this study stated that, within the conflicting messages they received and the pressures and the tensions within which they had to work, it is quite easy to misinterpret the real aims of integration.

They believed that integration is working and it can be beneficial when children with special needs are being included in the overall organisation of the school, working both alongside and together with their mainstream peers but having their own simultaneous groups for work when that is considered necessary. The notion of participation and continuity were key features of this integration programme.
Integration: an alternative way of thinking and teaching

Hoben (1980) claimed that:

defining the practice of mainstreaming as maintenance of handicapped students in regular education only reinforces that perceptions. But when the definition is expanded to include integration, then the mainstreaming becomes primarily a process of regular education which promises to benefit all students; not only handicapped students (p. 105).

In the case where integration becomes a regular educational practice it reaches a different level which includes not only students with special needs, but teachers, peers, subjects, activities and ideas. Different educational integrated activities have as an ultimate aim to include all children regardless of their gender, social-status, ethnicity and ability levels. It also reaches the level of connecting different aspects of life, one of which is disability, by integrating learning with living.

From the pragmatic perspective integration practices vary from class to class according to the dynamic of the class, the demands of the national curriculum for different levels, the characteristics that individual children with special needs 'possess', the teacher's philosophy of education, the teacher's personality, the nature of the relationship between regular and special teachers and the support system - both moral and practical - that a teacher has in her/his work.

Each of these elements plays its own significant role in the degree and the nature of inclusion of children with special needs in a ordinary class. These are elements that differentiate one classroom's atmosphere from the other's even when there is a whole school policy on the way integration should be implemented. However, what follows is a presentation and an analysis of those characteristics that help to facilitate integration at a whole school level.

Three characteristics were observed as being the key features for promoting integration of students with special needs: continuity, participation, and an extended notion of integration.

\section{Continuity}

Practices reflecting the notion of continuity are multidimensional and occur in different areas such as: continuity of a year's progress, of learning, of psychological development, curricula continuity and continuity of working relationships between home and school. The nature, the intensity, the level and the planning for continuity varied from one area to another.

The first area where planned continuity was observed was related to the actual year progress of the children with special needs. This involved connecting the pre-school life of the child with his or her entrance to the school, the year progress throughout primary schooling and finally, the creation of links with secondary schooling. Elements of coordination and liaison from "entry to exit points" were important for offering the opportunity to children to move from one environment to another. This practice of smoothing the transfer time is beneficial to all children but it is even more important to children with Down's syndrome due to their unease at shifting from one routine to another. 
Thus, initially, and before registration, teachers were being informed by parents about the potential of the child and his/ her strengths and weaknesses. In turn teachers informed parents of what the school could offer and what were its limitations. Further, the child was being offered the chance of meeting his/her possible peers and of spending informally some time with them being involved in the activities that went on in the class.

After the decision of registering the child at this school $\mathrm{s} / \mathrm{he}$ went on passing the years alongside his/her peers. There were, however, cases in which either the teacher or the parent felt it was necessary for the child's social and cognitive development to "repeat" the class. There was one case where the teacher's decision to keep a child with Down's syndrome at the same class was not in agreement with parents' opinion.

This shows that efforts to achieve year-continuity cannot always be applied to every child as it is a non-linear process with tensions and disagreements or even does not meet the child's needs. However, the majority of the children with special needs were moved up and they could be found in different classes in different years.

During the last year of primary schooling children were getting prepared for entering a new milieu that of the secondary school. In order to smooth out the transition, teachers had created exchange mechanisms according to which for some days both children with special needs and their peers were visiting different sections of the secondary school. Further, special teachers or the head of the secondary school resource centre were visiting the primary school in order to familiarise themselves with the children and exchange information with the teachers.

However, primary teachers expressed concern about a variety of issues that impinge upon their efforts to maintain and perpetuate this type of continuity. Firstly, they claimed that "there were too many children chasing too few places in the system". Thus, at the end there were children with special needs that were not going to be placed at a mainstream secondary school. They felt frustrated as they believed that these children were going to be placed either at special schools or other places far apart from their peers. They secondly maintained that the difficulty of the educational system at secondary levels to accept and educate these children has a restrictive effect upon the continuity of children's social and cognitive development. They believed that in these cases the efforts of so many years were "going astray".

Thirdly, they expressed particular concern about the lack of curricula continuity between primary and secondary schooling. Children had to move from an environment which was mainly "designed" to be child-centred to another environment which was mainly subject-orientated. They believed that in such a transition children's performance might deteriorate. Also they were sceptical about the support conditions that these children were going to be offered at secondary level, especially in cases where the other setting lacked the resources and the appropriate staffing to facilitate integration. For these reasons, teachers in charge of these transitions claimed that there was a need for further planning, information and linking mechanisms.
At a psychological level, as the children get older, teachers endeavour to promote independence. As a female teacher pointed out:

When they come at the end of this year and they go to the high school it is a giant step for them. They are going to a building that is enormous, and they are going to a school where the number of children is going to be six times more, and they are going to be with children that they don't know. I mean they do seem to solve it but you have to work on it and this is part of social training ... you have to offer space for independence.

Offering space for independence is not something that happens only during the last years with school but is being developed gradually according to the needs of the child. It is a process that takes with every child. Independence is one of the aims of education and one of the aims of integration.

\section{Continuity of learning:}

Teachers claimed that continuity of learning is an integral part of meeting children's needs. Continuity of learning and progression go together. In order to pursue this form of continuity teachers had devised:

Formal mechanisms: which included not only record keeping and assessment procedures but folders of pupils' work that were being given to the teachers of the following class. In this way there was a link between what the student had been taught and the learning-teaching strategies that were used. New and unknown information was linked with the already known. This process was found to be somehow more complicated when teachers had to deal with children with special needs. For instance, six teachers (two mainstream and three special teachers) stated that through their experience of teaching children with Down's syndrome they had figured out that the children had difficulties in combining skills that had been already taught in previous years. Teachers found it difficult to demonstrate in reports the complexity of this type of continuity, as there were multiple sub-levels of learning included in one level described by the National Curriculum.

Informal mechanisms: in which both mainstream and special teachers of different classes shared curriculum aims and objectives, teaching strategies, and experiences offering alternative scenarios. Co-operative learning reached teachers' levels. However, teachers complained that with all the administrative work they had to complete, time for such informal but crucial discussions becomes more and more limited.

Semi-informal mechanisms: in which group work that took place at a classroom level was being presented at a whole school level. The school valued all children's work both academic and non-academic, by presenting or displaying it in public areas of the school.

Practical mechanisms: in which one teacher had to inform the other teacher regarding the subject she was going to teach and the period of time she was going to teach it, as resources at times were too limited to be used by two different teachers in different classrooms at the same time. Further, two or three teachers teaching children of the same year were planning together teaching-learning strategies in or- 
der to apply them in joint classes.

School-home mechanisms: in which parents were considered essential contributors to the education of their child. This included a school-home teaching scheme in which children took work home. In this case parental involvement in teaching, reading, numeracy and social skills, has a beneficial input into children's development. In other instances parents were being invited to participate and help in activities that took place at school and which aimed to connect the school with the community. These types of linking mechanisms were extended with other interactive situations such as parents' evening meetings at school, parents-teachers reviews, and telephoned or written communication (2).

However, teachers were hesitant at including parents in everyday academic classroom activities. They also claimed that often it was very difficult to arrange face-to-face communicative situations with parents of children with special needs. They attributed this difficulty to the fact that parents lived quite far from the catchment area: a situation that had a negative effect not only on teacher-parent interactions but on the continuity of learning and socialisation of children with special needs and their peers. "Mixing at school" was not being expanded and linked with "mixing in the neighbourhood".

This indicates that integrated schools have not yet become neighbourhood schools; a fact that reproduces practices of separation similar to the ones generated by special schooling (3).

However, teachers did endeavour to minimise this discontinuity by providing opportunities in which the community was being linked with the school. Bearing in mind that in order for integration to make a difference peers should broaden their concept and understanding of themselves and of each other, teachers tried to integrate different aspects of life in which disability was a part.

\section{Participation}

Inclusion of children with special needs in the classroom is being promoted when the children have the opportunity to participate in class activities, to interact with their peers and to contribute to the learning outcome of the class.

Teachers stated that promoting interactions in a learning setting is one of the most challenging and difficult tasks they strive to accomplish. They believed that children with special needs do quite often need individual attention. In order to reach the demands of the National Curriculum a lot of individualised instructional teaching must take place. These conditions encompass the danger of fragmenting children with special needs from their peers.

Within these tensions they tried to structure their classes and to organise the learning activities in such a way as to promote participation and co-operation. They started from the point that children with special needs were part of the whole class; thus, they did alter both the learning and teaching strategies.

Practically, children with special needs could be found in different places in the class sitting and working with their peers with the teacher, both special and regular, taking the role of the facilitator. This seating arrangement helped children to mingle with each other or to help and be helped. Full inclusion was taking place during physical education and music time in which all children were working as a group or in different groups. During physical education a lot of symbolic and pretend play was taking place accompanied by music.

The significance of involving children in this type of semistructured play situation has been reported by a number of researchers (Schwartzman, 1978; Garvey, 1977; Stambak et. al 1985). According to them the most important function of pretend play is the negotiation of shared meaning systems within which the fantasy action, whatever its specific content, may be understood by the players.

The interactive processes which pretend play includes, promote not only the development of social interaction skills but also cognitive development. In this kind of play children are capable of abstracting from their play theme the social interaction's implicit rules. From observation it was found that in the playground children with Down's syndrome quite often initiated pretend-play interactions which their peers enjoyed participating in.

Co-operative grouping took place when teaching 'coresubjects' as well. Subject-integration was considered by the teachers as an important principle for facilitating mixedability co-operative learning. Children could work on a group activity which included different sub-tasks of mixedsubject orientated topics requiring different levels of ability and skills, peer teaching being an alternative strategy for promoting interactions and mutual learning.

Teachers, however, found it difficult to match these subjectintegrated activities with the directives of the National Curriculum. They believed that the National Curriculum presents different subjects in a segregated way without taking into consideration that in every class there are students with certain limitations. They also felt that this is happening because the National Curriculum was designed mainly to respond to the more subject-orientated secondary schools' activities.

Even though teachers felt that such structuring needs time, flexibility and diversity of staffing, they believed that subjectintegrated activities helped them to keep all children's interest by offering them chances for participation, interaction, and creation.

\section{Broadening the notion of integration}

A lot of curricula activities and most of the extra curricular activities aimed to broaden children's interests, to develop the notion of inclusion, to offer a variety of stimuli and situations in which children could participate with a critical mind. Environmental activities, activities which offered the opportunity to children to mix with elderly or disabled people from the neighbourhood, or that would help people suffering from poverty and wars, were some of the activities that children were involved in and they were offered the chance not only to "give" but to benefit from the continuous process of learning.

Simultaneously, the school invited guests such as firemen, policemen, priests, doctors, people with disabilities, representatives from other countries, in order to promote an awareness of different aspects of life. Thus, it is a matter of 
attitudes as well and not only a matter of technical programming which has to be implemented as a strictly educational and administrative task.

From this perspective integration does make a difference because it enhances the children's knowledge of the world, it widens their environment and has a beneficial impact on their social and cognitive development. As a male teacher pointed out when asked to refer to some of the benefits deriving from integration:

I think it's a two way process that the children in the integrated resource do offer the school an awful lot, they receive an awful lot back, perhaps they receive more than they give but they do give an awful lot to the school.

\section{Conclusion}

Integration does make a difference to the way teachers perceive the aims of education and their roles as educators. In this paper, it was shown that integration is a two way process which benefits not only students with special needs but their peers as well. Continuity, participation and an extended notion of integration were crucial elements beyond the practices that the school have adopted in order to meet children's needs. However, the implementation of these three characteristics demands that integration is an inherent aim of ordinary education instead of a technical/ administrative programme transplanted into schools.

\section{Notes}

(1) The author would like to note that the titles of some of these articles and journals use a disabling language; a terminology that I strongly believe has negative effects on our assumptions and attitudes towards disabled people.

(2) Readers are encouraged to review the work of Wolfendale, S. (1987) Special Needs in Ordinary Schools for further elaboration of this finding.

(3) Also the work of Meighan, R. (1981) A Sociology of Education deals theoretically with this aspect.

\section{References}

Bromfield,R., Wiz,J and Messer,T. (1986) Children's judgements and attributions in response to the mentally retarded label: a developmental approach. Journal of Abnormal Psychology, 95, 81-87.

Buckley,S.J. and Sacks,B. (1987) The adolescent with Down's syndrome: life for the teenager and for the family. Portsmouth Polytechnic.

Carroll,A. (1967) The effects of segregated and partially integrated school programs on self concept and academic achievement of educable mentally retarded. Exceptional Children, 34, 93-96.

Casey,W., Jones,D., Kugler,B. and Watkins,B.(1988) Integration of Down's syndrome children in the primary school: A longitudinal study of cognitive development and academic attainments British Journal of Educational Psychology, 58, 279-286.
Dandy,J., and Cullen,C. (1988) Integration and mainstreaming: a review of the efficacy of mainstreaming and integration for mentally handicapped pupils. Educational Psychology, 8, 3, 332-341.

Dessent,T. (1987) Making the Ordinary School Special, Falmer Press, London.

Garvey,C. (1977) Play: The Developing Child, Fontana Press, Great Britain.

Gickling,E. and Theobald,J. (1975) Mainstreaming: affect or effect. The Journal of Special Education, 9, 317-328.

Gottlieb,J. (1974) Attitudes towards retarded children: effects of labelling and academic performance. American Journal of Mentally Deficiency, 79, 3, 268-273.

Hegarty,S. (1989) Past, current and future research on integration: an NFER perspective. In Jones, N. (ed.), Special Educational Needs Review, 1.7-18.

Hoben, M. (1980) Towards integration in the mainstream. Exceptional Children, 47, 100-105.

Jenkins,J., Odom,L and Speltz,M. (1989) Effects of social integration on pre-school children with handicaps. Exceptional Children, 55, 5, 420-428.

Johnson,T. and Johnson,D. (1981) Building friendships between handicapped and non handicapped students: effects of co-operative and individualistic instruction. American Educational Research Journal, 18, 4, 415-423.

Karagiannis,T. (1988) Attitudes Towards Integrating Children with Down's Syndrome. Unpublished Master Thesis, McGill University, Montreal, Canada

Meighan,R. (1981)A Sociology of Education, Holt, Rinehart and Winston, London.

Pieterse,M. and Center,Y. (1984) The integration of eight Down's syndrome children into regular schools. Australia and New Zealand Journal of Developmental Disabilities, 10, 1, 11-20.

Schwartzman,H. (1978) Transformations: The Anthropology of Children's Play. Plenum Press, London.

Slee,R.(1993) The politics of integration: new sites for old practices? Disability, Handicap and Society, 8, 4, 351-360. Stambak,M., Ballion,M., Breaute,M. and Rayna,S. (1985) Pretend Play and Interaction in Young Children. In Hinde, R., Clermont,A. and Hinde,J. (Eds.), Social Relationships and Cognitive Development. Oxford Science Publications: A symposium of the Fyssen Foundation, England.

Uditsky,B. (1993) From Integration to Inclusion: The Canadian Experience in Slee,R. (Ed.) Is There a Desk With my Name On It: The Politics of Integration. The Falmer Press, London.

Wolfendale,S. (1987) Special Needs in Ordinary Schools: Primary Schools and Special Needs, Policy, Planning and Provision, Biddles Ltd, London.

Address for correspondence:

University of Sheffield,

Division of Education,

338 Glossop Road,

Sheffield, S10 2JA,

U.K. 